\title{
The effects of heat treatment on the microstructure and microhardness of explosive welding
}

\author{
Fehim Findik $^{1,2 \star}$, Ramazan Yilmaz ${ }^{1}$ and Tolga somyurek ${ }^{1}$ \\ ${ }^{1}$ Technical Education Faculty, Sakarya University, 54090 Esentepe Adapazari, Turkey. \\ ${ }^{2}$ Faculty of Engineering and Natural Sciences, International University of Sarajevo, Hrasnicka Cesta 15, 71000 Sarajevo, \\ Bosnia-Herzegovina.
}

Accepted 28 July, 2011

\begin{abstract}
An AISI 304 type of austenitic stainless steel and low carbon steel were cladded by explosive welding in this study. Four explosive loading rates were used with the range of 1 and 2.0. Stand-of distance ( $s=t)$ was also used as a welding parameter. Cladded materials have been subjected to heat treatment at $250^{\circ} \mathrm{C}$ for times of ranging from 1 to $4 \mathrm{~h}$. Effect of heat treatment on the microstructure and mechanical properties has been evaluated using optical and scanning electron microscopy, EDS analysis technique and hardness tests, respectively. The results indicate that straight and wavy structures of bonding at the interface were obtained according to the loading of explosive rate. The grain size of the cladded materials near the interface were increased with the duration of heat treatment. Hardness values at the interface of the cladded materials were decreased with the increment of heat treatment period.
\end{abstract}

Key word: Explosive welding, hardness, microstructure, stainless steel, low carbon steel.

\section{INTRODUCTION}

Explosion welding is one of the joining methods consisting of a solid state welding process in which controlled explosive donation on the surface of a metal. During the collision, a high velocity jet is produced to remove away the impurities on the metal surfaces. Flyer plate collides with base plate resulting in a bonding at the interface of metals. The metal plates are joined at an internal point under the influence of a very high pressure and causes considerable local plastic deformation at the interface in which metallurgical bonding occurs in nature and even stronger than the parent metals (Crossland, 1971,1976; Linse et al., 1984; Vonne et al., 1984; Brasher et al., 1995).

Current developments in advanced technologies require new materials with superior properties such as corrosion, wear resistances for industrial applications. Therefore, numerous works have been carried out to develop new materials for such purposes. As low carbon

*Corresponding author. E-mail : ffindik@ius.edu.ba. Fax: + 387957105.Tel: + 387-957220. steel has low corrosion resistance therefore, it may be cladded with the materials such as aluminium, titanium and stainless steel that can be suitable for using in corrosion environment. Explosive welding is a well known for its capability to directly join a wide variety of both similar and dissimilar combinations of metals that cannot be joined by any other techniques. Furthermore, the process is capable of joining with high surface areas due to its ability to distribute the high energy density through explosion (Crossland, 1971, 1976; Vonne et al., 1984; Brasher et al., 1995). Up to now, low carbon steel (Acarer et al., 2003; Ghanadzadeh et al., 2003), steel and aluminium (Han et al., 2003; Balasubrahmanian et al., 1997; Acarer et al., 2008; Du et al., 2007), steel and titanium (Ege et al., 1998; Mousavi et al., 2008, 2009; Kahraman et al., 2005), nickel film and aluminium alloys (Gerland et al., 2000), duplex stainless steel and low carbon steel (Kacar et al., 2003), iron and copper (Livne et al., 1987; Durgutlu et al., 2005; Kahraman et al., 2005), titanium and austenitic stainless steel (Mudali et al., 2003), aluminium, copper and magnesium (Fan et al., 2003; Watanabe et al., 2009; Gulenc, 2008; Ghaderi et al., 2008) were cladded successfully. 


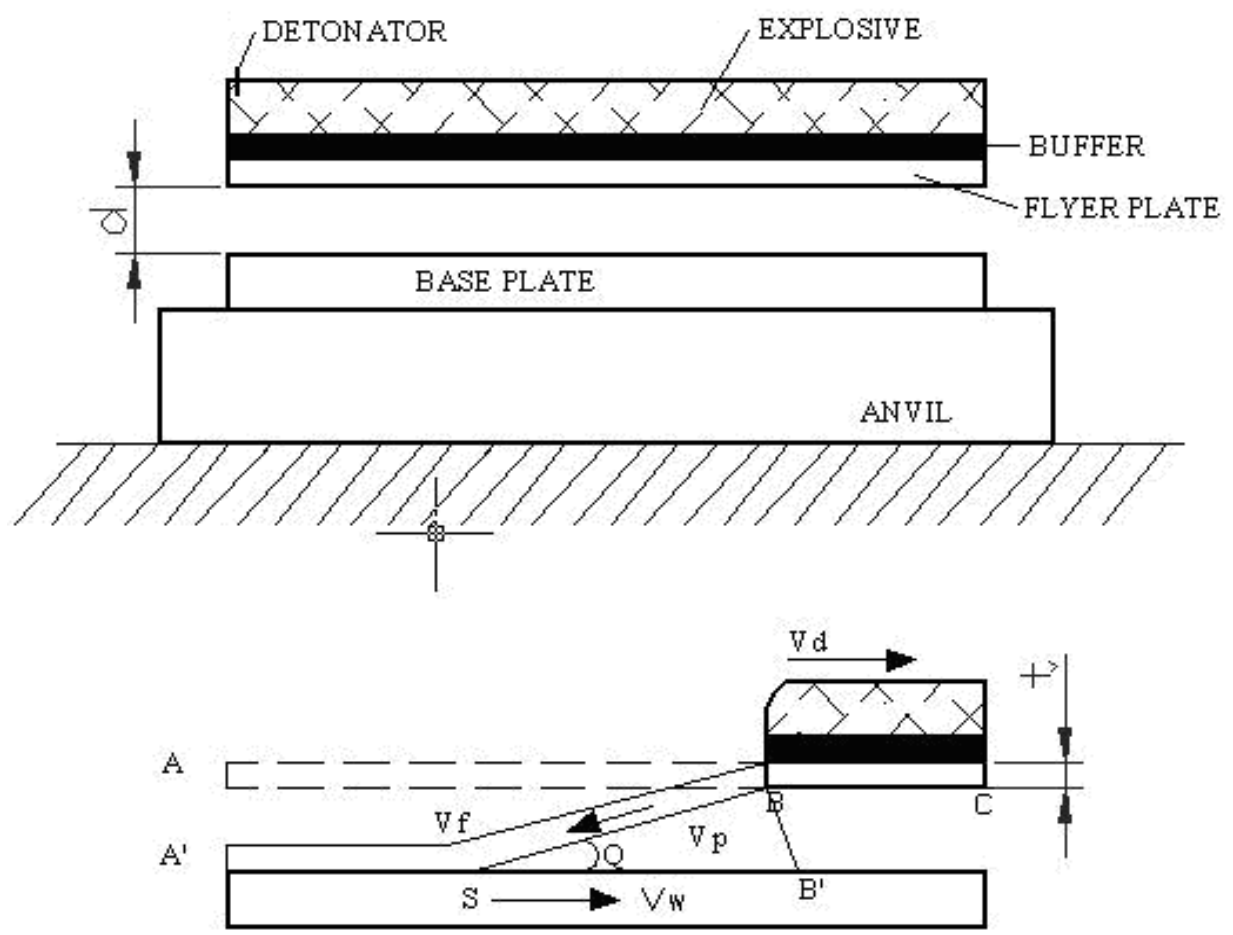

Figure 1. Schematic diagram of a set-up for the explosive welding process.

Explosive welding is also useful for producing a thin surface sheet with a minimal reduction in ductility. Despite that, the explosive welding is a dangerous method due to using explosives for joining, it is successfully possible to join unweldable materials using this method. Therefore, many bimetallic combinations can be easily generated offering designer broad possibilities. Some advantages of explosive welding over conventional joining methods are as follows:

(i) There is no heat affected zone in weldment materials compared with the conventional methods. Superior properties and performance of the materials could be achieved.

(ii) Applicability of explosive welding is getting wide day by day due to its low cost process that results in high performance, and complex shaped components (Crossland, 1971,1976; Vonne et al., 1984; Brasher et al., 1995; Kahraman et al., 2007; Inal et al., 1997).

AISI 304 type of austenitic stainless steel is widely used materials in the current industrial applications such as pressure vessels, chemical tankers and pipes, due to its superior corrosion resistance and mechanical properties (Smith, 2000; ASM, 1983).

The aim of current work was to show that low carbon steel cladded with 304 stainless steel may be of an alternative in using stainless steel alone. By doing this, cheaper materials could be replaced with an alternative one. In this case, stainless steel with a low carbon steel was cladded with high corrosion resistant stainless steel. Although it can be said that there is no heat affected zone in the cladding materials, sometimes stress relief annealing may be needed. More recently work has been focused on the explosive welding of steel and steel, studying the effect of heat treatment on the hardness and strength values of cladding materials and resulted in higher strength and lower in hardness values at the interface (Ghanadzadeh et al., 2003).Therefore, researchers are needed to be preformed on the effect of heat treatment on the properties of cladding materials by explosion welding to enhance their performances.

The present work is concerned with an investigation of heat treatment on the properties of 304 types of austenitic stainless steel and low carbon steel plates cladded by explosive welding with different rate of explosives at $250^{\circ} \mathrm{C}$ for 1 to $4 \mathrm{~h}$. The study involves a detailed microstructural analysis using variety of techniques including optical, SEM, EDS and parallel hardness measurement at the interface. Experimental observations were evaluated and then discussed with the earlier works.

\section{EXPERIMENTAL PROCEDURES}

Experimental set-up arrangement for explosive welding is given schematically in Figure 1. Due to superior mechanical and corrosion properties of austenitic stainless steel, 304 type stainless steel was chosen as a flayer plate while Erdemir 6182 low carbon steel was used a base plate. The chemical compositions of materials used 
Table 1. The chemical composition (wt. \%) of the AISI 304 stainless steel and low carbon steel.

\begin{tabular}{|c|c|c|c|c|c|c|c|c|c|c|}
\hline \multirow{2}{*}{ Materials } & \multicolumn{10}{|c|}{ Elements (wt.\%) } \\
\hline & C & Mn & $\mathrm{Si}$ & $\mathbf{P}$ & 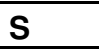 & $\mathrm{Cr}$ & $\mathrm{Ni}$ & Mo & $\mathrm{Cu}$ & $\mathrm{Fe}$ \\
\hline AISI 304 & 0.08 & 2 & 1 & 0.045 & 0.045 & 19 & 10 & - & - & Balanced \\
\hline E-6182 & 0.043 & 0.225 & 0.004 & 0.012 & 0.01 & 0.027 & 0.003 & 0.012 & 0.297 & Balanced \\
\hline
\end{tabular}

in this study were given in Table 1 . Flyer and base plates were designed with dimension of $200 \times 200 \times 1.5 \mathrm{~mm}$ and $200 \times 200 \times 2 \mathrm{~mm}$, respectively. Rolled steel plate was used as an anvil with the dimension of $2000 \times 1500 \times 50 \mathrm{~mm}^{3}$. The surface of the base and flyer plates were used as received. The ELBAR 5 (ammonium nitrate $90 \%$ min $4.5 \%$ fuel-oil and $\min 3 \%$ TNT) was chosen as explosive material which was produced by MKE Barutsan Company in Kırıkkale, Turkey. The detonation velocity of the explosive material is about 3000 to $3200 \mathrm{~m} . \mathrm{s}^{-1}$. The density of explosive materials is $0.8 \mathrm{~g}_{\mathrm{cm}} \mathrm{cm}^{-3}$. The explosion rate and stand of distance of the flyer plate was set up ( $R=1.0$ to 2.0$)$ and ( $\mathrm{s}=\mathrm{t}$, flyer thickness) respectively, prior to detonation.

A series of heat treatment were performed in order to investigate the effect of heat treatment on the microstructure and hardness properties of the cladded materials. Specimens of cladded materials were heat treated in air at $250^{\circ} \mathrm{C}$ for periods of time ranging from 1 to $4 \mathrm{~h}$ using in a muffle furnace.

For microstructural examination, polished sections were prepared by first extracted from cladded material parallel to explosion with the dimension of $20 \times 10 \mathrm{~mm}$. Then, they were mounted in bakelite for microstructure and hardness examination. Mounted sections were flatted by 400 grid $\mathrm{SiC}$ abrasive paper and samples were ground on successively finer grades of silicon carbide paper down from 400 to 1200 grit. The samples were then lightly polished using 6 and $1 \mu \mathrm{m}$ alumina slurry, followed by a further minute with a water wash. Polished sections of base plate was etched with $2 \%$ Nital solution while stainless steel side of cladded material section was polished with solution of mixed $1 \mathrm{ml} \mathrm{HCl}+1 \mathrm{ml} \mathrm{HNO}_{3}+1 \mathrm{ml} \mathrm{H} \mathrm{H}_{2} \mathrm{O}$. The metallographic examinations were carried out using optical and scanning electron microscope (SEM) that equipped with an energydispersive X-ray spectrometry (EDS) system.

Hardness measurement of cladded material was carried out with IHV-501 E TIME model microhardness test machine. During the test, a $25 \mathrm{~g}$ load was applied and hardness measurements took place in every $20 \mu \mathrm{m}$ intervals at the interface of cladded materials.

$X$-ray diffraction studies were carried out to identify phases in the structure of the heat treated sample at $250^{\circ} \mathrm{C}$ for $4 \mathrm{~h}$. X-ray diffraction study was performed using a Shimadzu diffractometer model XRD-6000 using $\mathrm{Cu} \mathrm{Ka}$. radiation with a wavelength of $1.5405 \AA$.

\section{RESULTS}

It was found that cladding of AISI 304 type of austenitic steel to low carbon steel was achieved successfully by the technique of explosive welding. Optical microstructural study showed that both wavy and straight morphology occurred at the interface (Figures 2 and 3). Although, wavy interface was obtained with the loading rate of 1.2, 1.6 and 2; it is distinctly seen in the sample explosively welded with the loading rate of 2 . Occurrences of straight and wavy interfaces were depending on welding parameter. In this study, wave length and amplitude increased with rising of explosive loading (Acarer et al., 2003; Mudali et al., 2003). Higher amount of explosive loading increases with the impact energy of flayer plate. Therefore, interface structure can be changed from straight to wavy form. Researches on interface structure indicate that straight or wavy structure at interfaces does not affect the mechanical properties (Acarer et al., 2003; Smith, 2000). The morphology of the interface verifies that explosive loading was sufficient to obtain a wavy interface. The loading rate of 1 showed that straight morphology was occurred at the interface. Wavy interface occurs with the increasing of explosive loading. However, interface morphology depends on not only explosive rate but also the angle and stand off distance between flyer and base metals. All angles and the explosive rate stand wavy morphology at interface with explosive loading rate of 2 could be attributed to producing the highest value of $\beta$ angle that may be occurred during the explosion. This was in line with literature (Kahraman et al., 2007). High detonation velocity can give rise to a relatively large value of angle $\beta$, thereby creates a strong turbulence at the interface. The metallurgical bonding was occurred between explosively welded metal. The interface between low carbon steel and AISI type 304 austenitic stainless steel was found to be generally smooth and perfect without significant defective zone.

Microscopic examination also showed that the grains of the low carbon steel and AISI 304 types of austenitic stainless steel elongated in the direction of the explosion, especially just near to the interface. This is possibly due to the plastic deformation caused by the high velocity impact of the explosion.

The hardness values of heat treated samples that were cladded materials with the loading rate of 1 are shown in Figure 4. The samples were heated for $2 \mathrm{~h}$ and they show slightly lower hardness values than that of as cladded material with the value of $181 \mathrm{HV}$. The samples heated for 1,3 and $4 \mathrm{~h}$ show similar hardness at the interface with the values of 135, 128, $126 \mathrm{HV}$ respectively. However the sample heated for $4 \mathrm{~h}$ shows the lowest hardness values on the side of stainless steel of all. The similar hardness values were obtained on the side of low carbon steel at the interface.

The hardness variation of heat treated samples that cladded with explosive rate of 1.2 is shown in Figure 5 . As seen from the figure, the hardness values at the interface decrease with an increase in heat treatment 

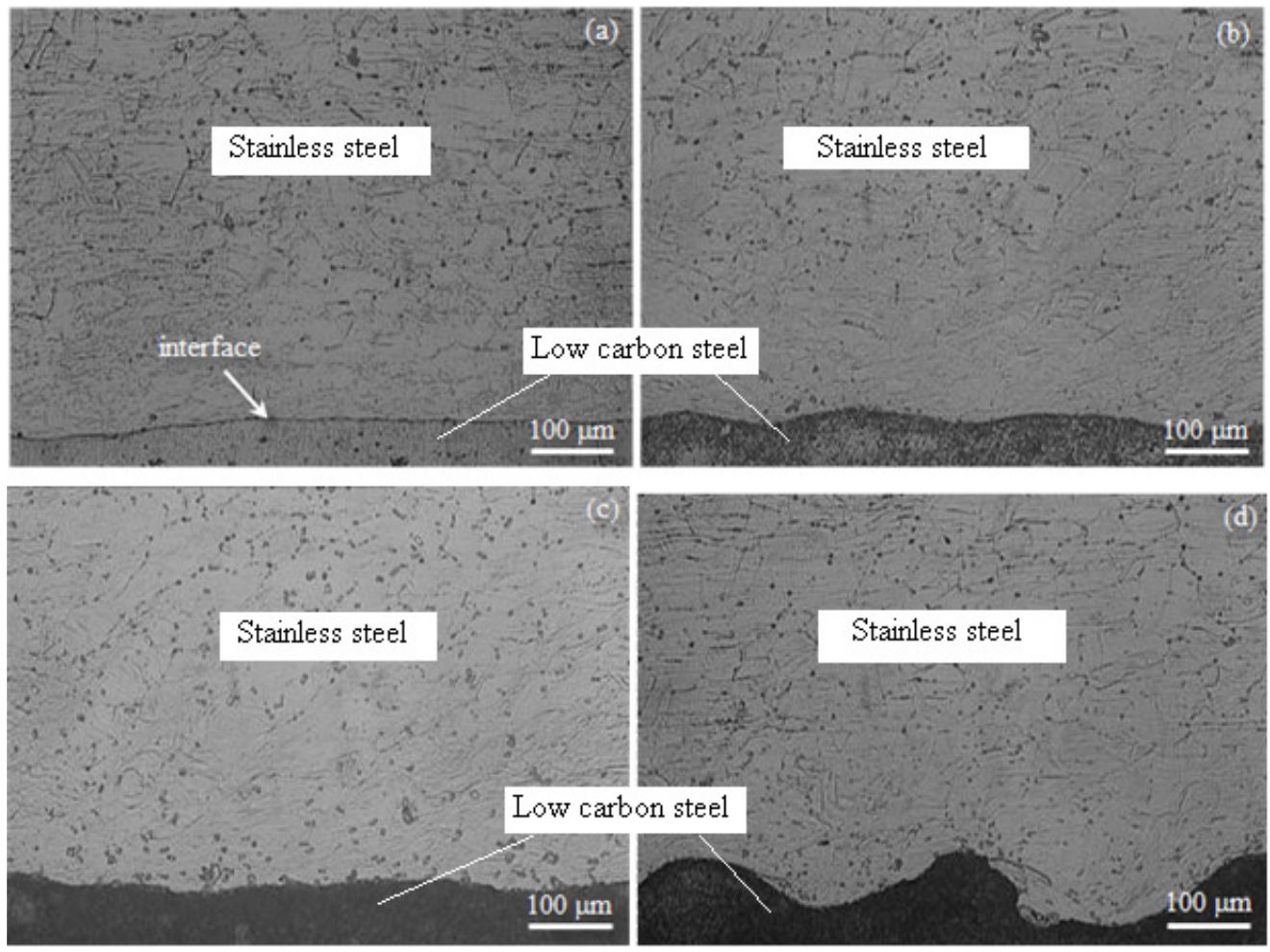

Figure 2. Optical microscopy showing interfaces of the austenitic stainless steel side AISI 304 type austenitic stainless /low carbon steel with the explosive load of a) 1 b) 1.2 c) 1.6 d) 2.
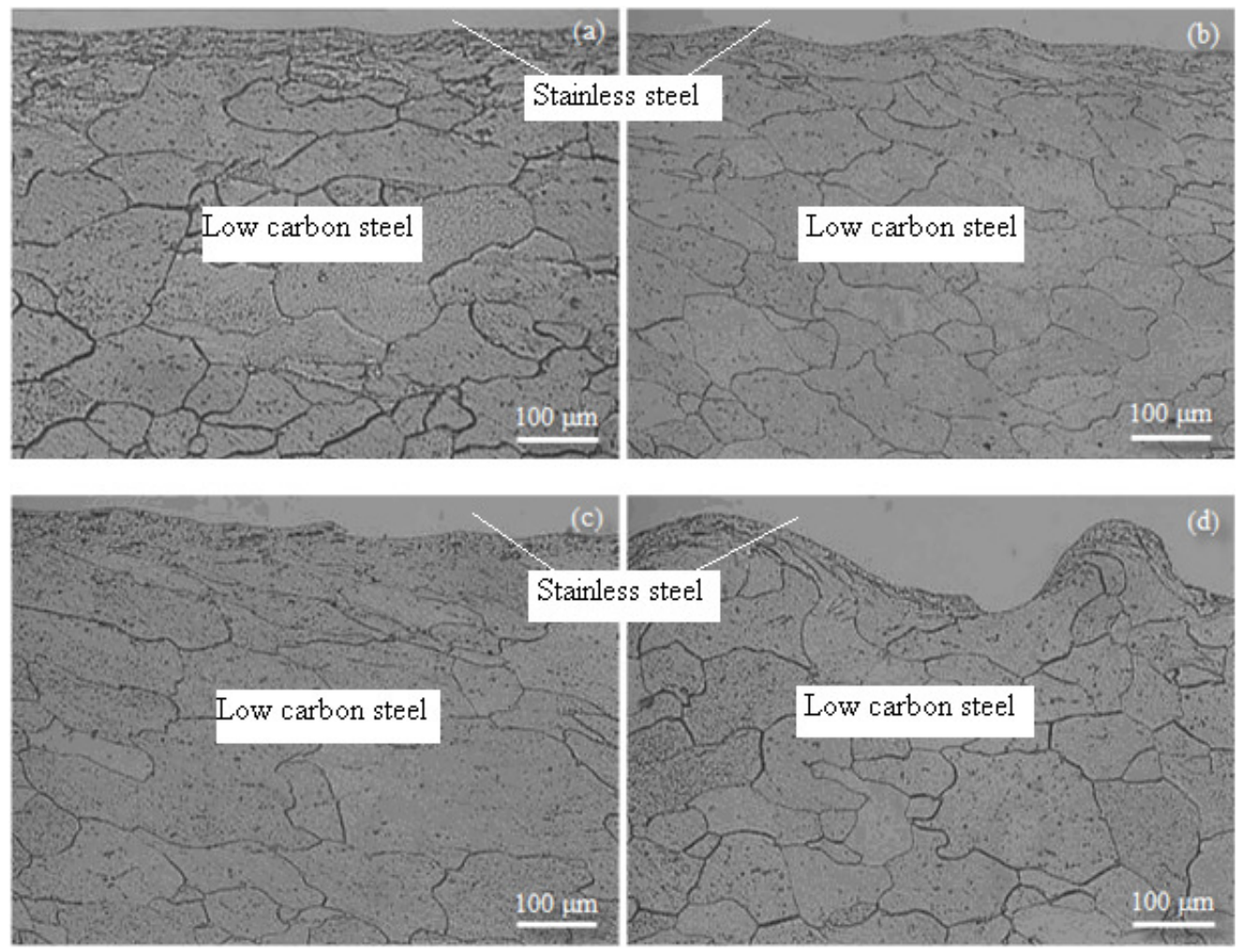

Figure 3. Optical microscopy showing interfaces of low carbon steel side AISI 304 type austenitic stainless /low carbon steel with the explosive load a) 1 b) 1.2 c) 1.6 d) 2. 


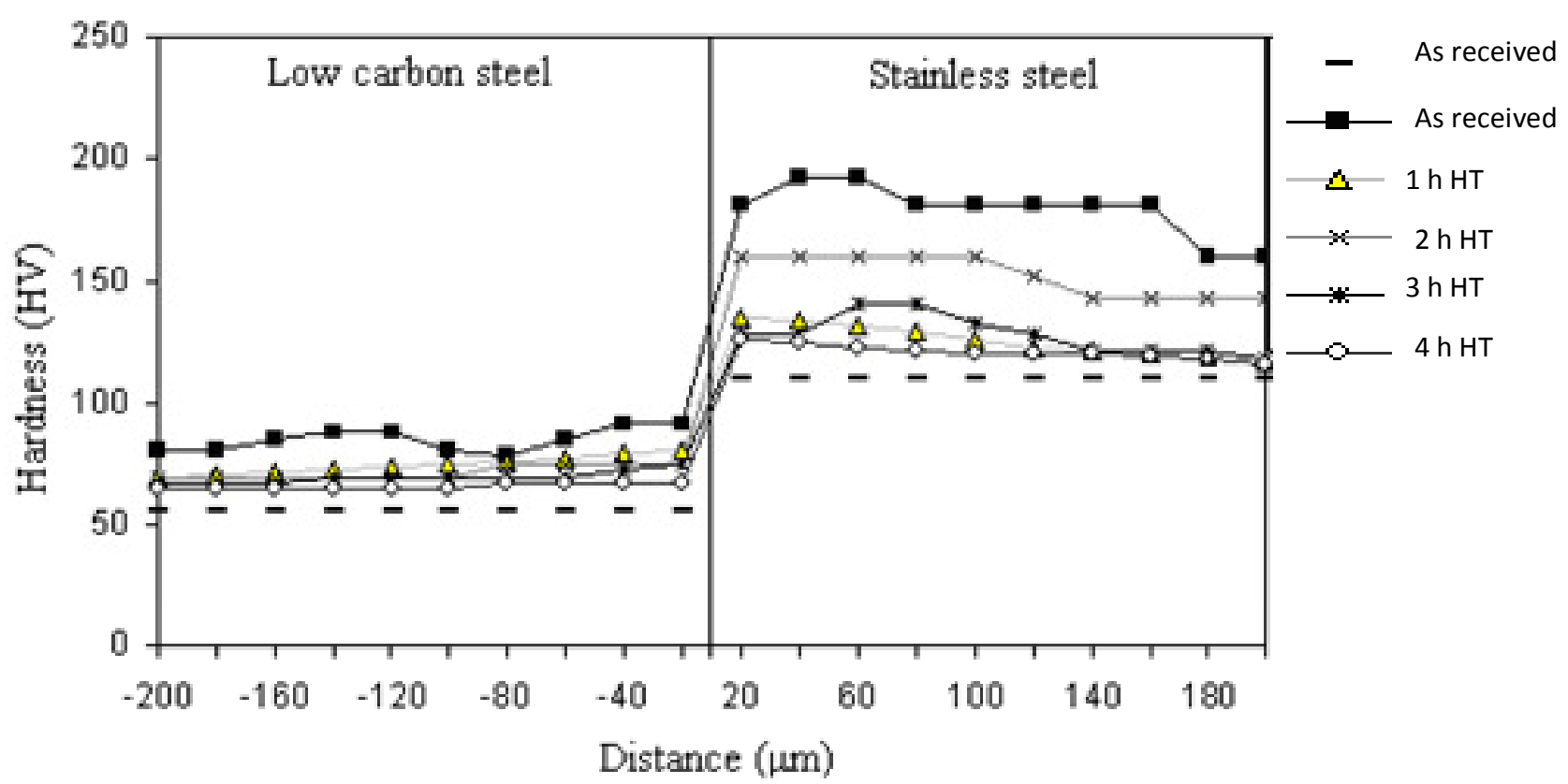

Figure 4. Microhardness variation across the stainless steel and low carbon steel explosive joints with loading rate of 1 $[R=1]$.

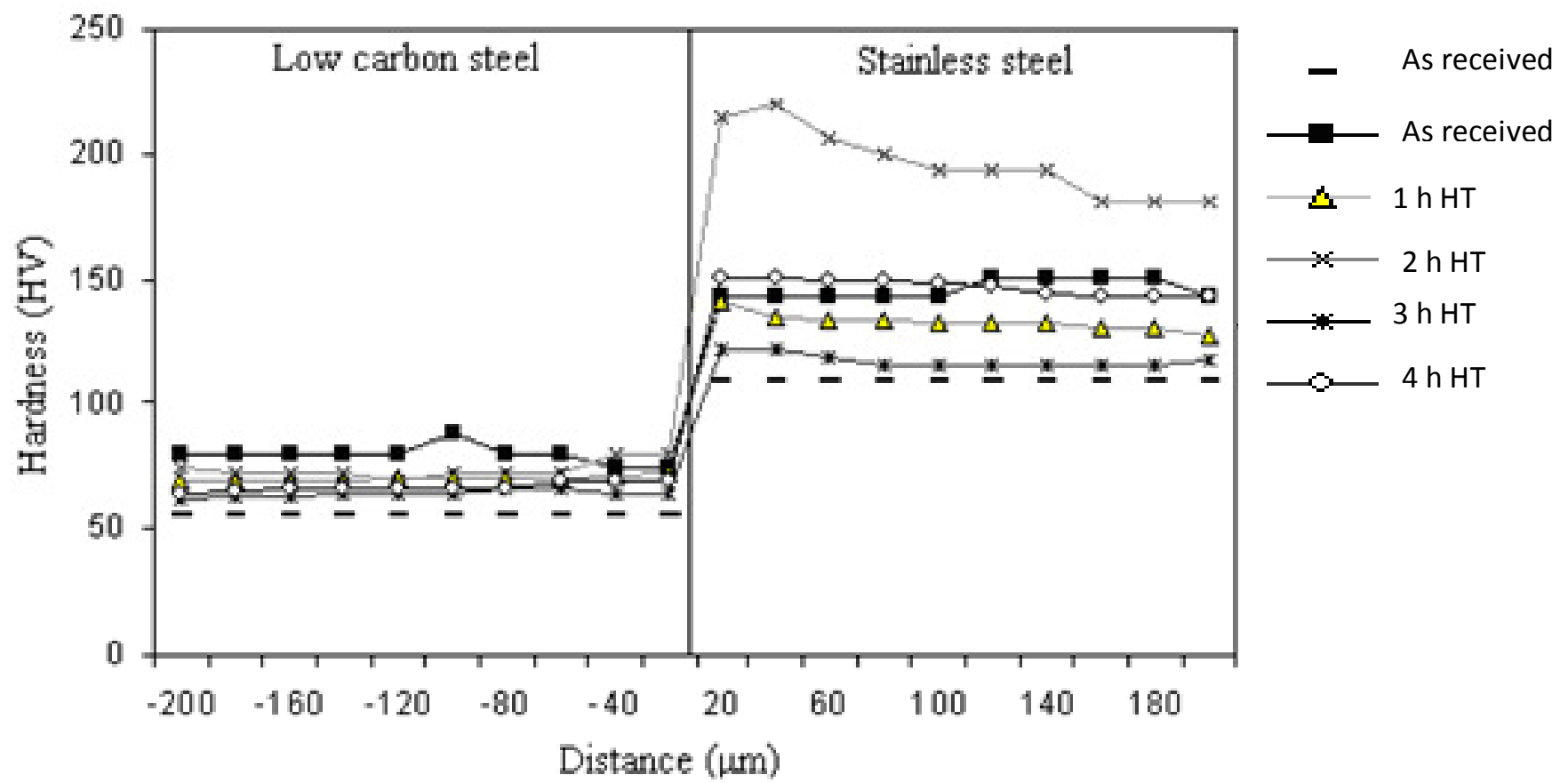

Figure 5. Microhardness profile across the stainless steel and low carbon steel explosive joints with loading rate of 1.2 [R=1.2].

durations. The increasing rate is about $50 \%$ compared with as cladded materials. Samples heat treated for $2 \mathrm{~h}$ at $250^{\circ} \mathrm{C}$ showed the highest hardness values. The reason for this is due to the recrystallisation process of the materials at this specific temperature and time.
Recrystallisation may occur during or after deformation. In the present case, plastic deformation occurred due to the impact of two sheet metals (low carbon and stainless steel) during explosive welding. In the first step of recrystallisation, a lot of small grains occur due to 


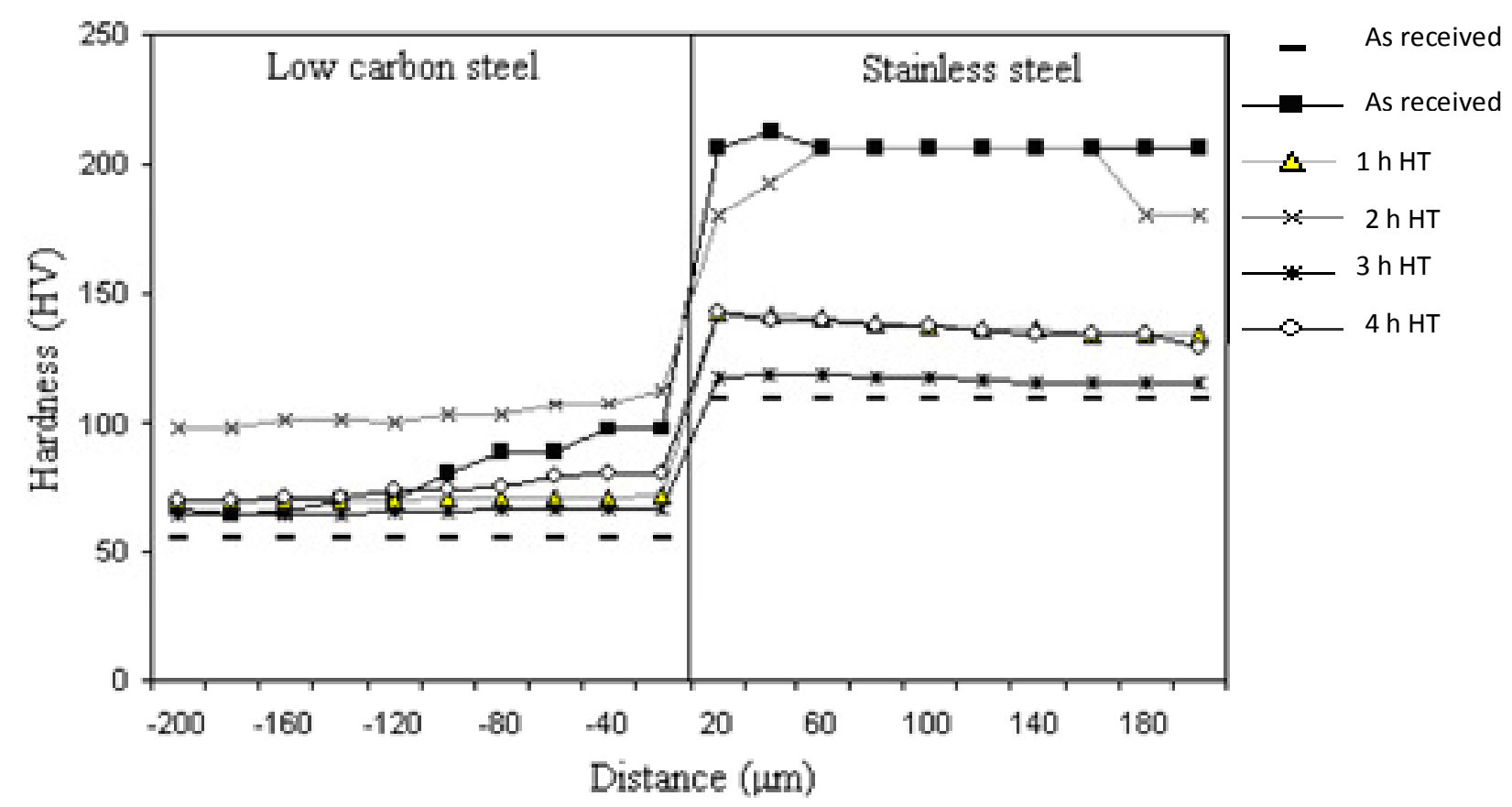

Figure 6. Microhardness profile across the stainless steel and low carbon steel explosive joints with explosive loading rate of $2[R=2]$.

nucleation in a particular temperature. These small grains have longer grain boundaries and they are the barrier for dislocation movement. That is why the hardness is the highest at this specific temperature and time. The hardness values of the samples heat treated with the duration of 1, 3 and $4 \mathrm{~h}$ showed similar values.

The hardness results after heat treatment of cladded materials are given in Figure 6 . As can be seen from the figure that sample heated for $2 \mathrm{~h}$ shows higher values of hardness than that of as received material. The hardness of the sample that was exposed to heat treatment at $250^{\circ} \mathrm{C}$ for two hours shows almost the same result with that of as cladded material. It is particularly interesting to note that the hardness of the sample heated for two hours shows highest hardness values of all the samples that cladded by explosive welding with various explosive loading. The other heat treated samples for 1, 3, 4 show lower hardness values than those of as cladded materials.

\section{DISCUSSION}

Microstructural study shows that interfacial structure exhibits wavy and straight shape (Figures 7 and 8). Heat treatment process resulted in a grain coarsening over long heat treatment duration. This was consistent with the previous study (Acarer et al., 2003). Actually, all cladded samples by explosion welding show elongation in explosion direction and heat treatment does not change the grain geometry. However, grain size of low carbon steel side while on the side of 304 austenitic stainless steel exhibits very fine grain slightly increases at longer heat treatment period.

Figure 9 shows the hardness values of the samples of cladding stainless steel to low carbon steel under various explosive loading. The samples cladded with the loading rate of 2 shows the higher hardness values on the stainless steel side interface with the values of $212 \mathrm{HV}$. This shows an increase in hardness from as received materials of about $87 \%$ than the mild steel side with the loading ratio of 1.2 shows the lowest hardness values at the side of stainless steel. The difference between the values of the as received and cladded one is about $30 \%$. The original hardness of the low carbon steel and AISI 304 austenitic stainless steel are 60 and 115 HV, respectively. However, hardness values of stainless steel increased much more than the low carbon steel, which may be attributed to the high work hardening capacity of those of low carbon used in this study. Hardness values decrease away from the interface, this is possibly due to the high amount of the plastic deformation which may be occurred at the interface. Similar observation was also obtained in the earlier study (Acarer et al., 2003).

High value of hardness near the interface of 304 type austenitic steel in the explosive bonded joint could be attributed to the high degree of deformation of stainless steel during the explosive welding process. When austenitic stainless steels are deformed, martensite formation and the dislocation density within the host 

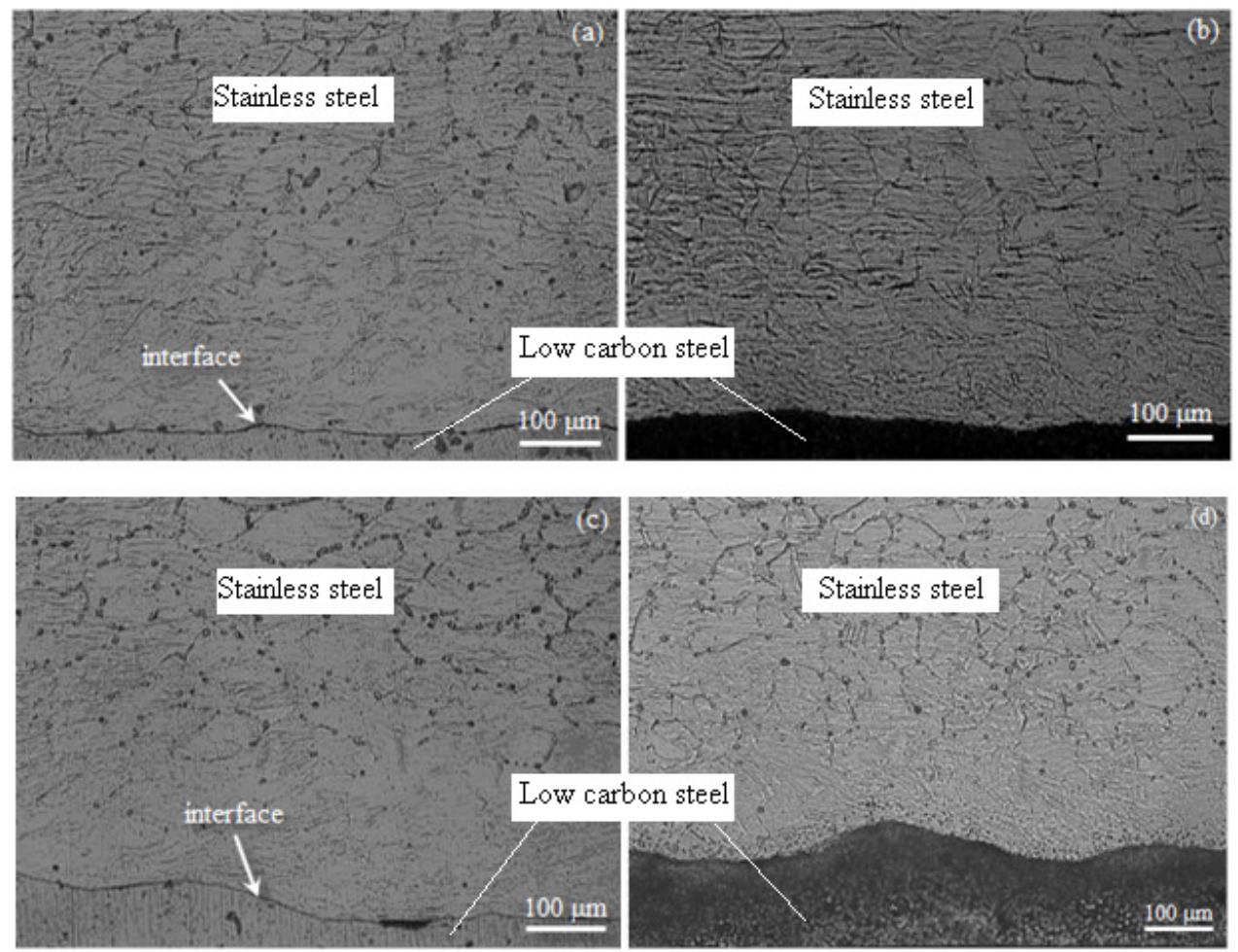

Figure 7. Optical micrograph from stainless steel side interfaces between AISI 304 type austenitic stainless /low carbon steel subjected to heat treatment at $250^{\circ} \mathrm{C}$ with explosive load of a) 1 b) 1.2 c) 1.6 d) 2 .
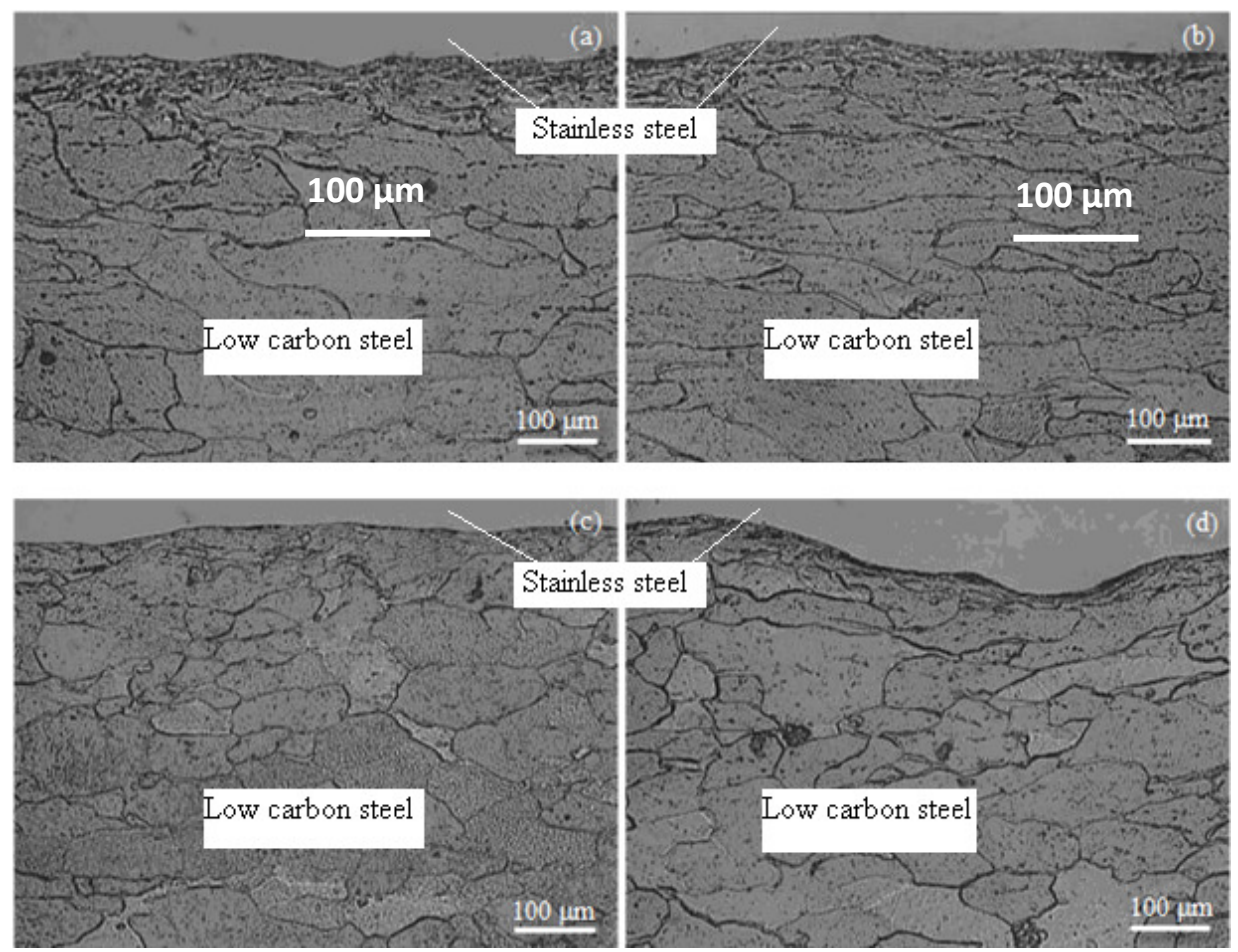

Figure 8. Optical micrograph from low carbon steel side interfaces between AISI 304 type austenitic stainless /low carbon steel subjected to heat treatment at $250^{\circ} \mathrm{C}$ with explosive load of a) 1 b) 1.2 c) 1.6 d) 2 . 


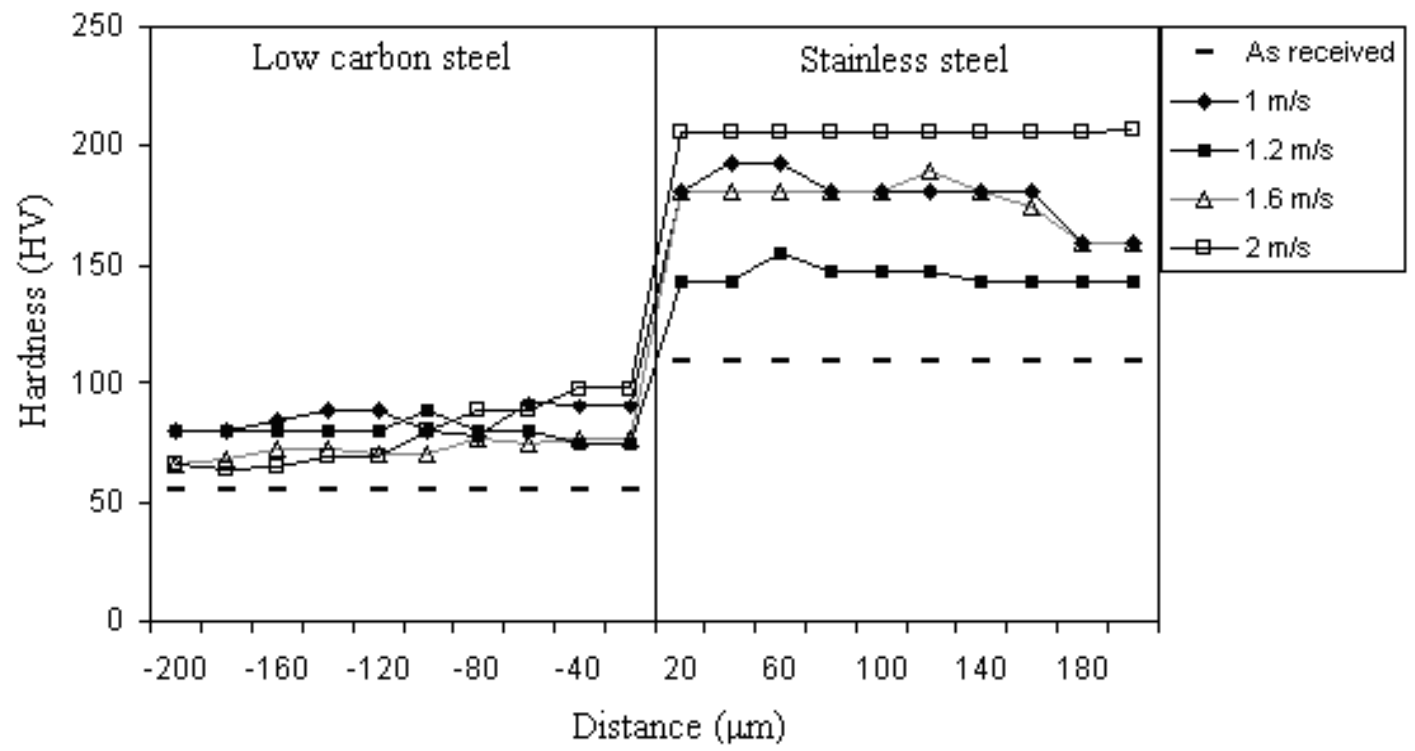

Figure 9. Microhardness profile across the stainless steel and low carbon steel explosive joints with various explosive loading rate.

material increase in accordance with the amount of deformation. The density of dislocations is in the range between 108 to $1012 \mathrm{~mm}^{-2}$, which increases with the plastic deformation of metals (Abe, 1999). The hardness and strength of the material increase with the increment of density of interrupting of dislocations. Finer grain size results in increasing the hardness and strength of the material and in decreasing the ductility of the metals. In the present study, the finer microstructure of 304 type austenitic stainless steel (Figure 2) performed higher hardness (Figures 4 to 6 ) during the explosive welding.

The phase transformation due to plastic deformation was observed in AISI 304 stainless steel in earlier study (Dieter, 1988). The gradual transformation of austenite to strain induced martensite increases the work hardening of the steels. Stainless steel changes from fcc to bcc structure by the martensitic transformation. The dislocation density increases considerably with the increment of deformation. The fine grained martensite makes dislocation motions more difficult. Work hardening leads two distinct products in the affected material, the formation of martensite and increasing of dislocation densities (Takahashi et al., 2001). The band structure of dislocations appears with an increase in strain. In this study, the increase in hardness of the interface is mainly associated with the fine grains. Severe plastic deformation contributed to grain refinement due to dynamic recrystallisation. Due to application of martensite transformation and subsequent tempering, formation of microcrystalline structure and phase transformation in austenitic stainless steel were reported (O'sullivan et al., 2003; Belyakov et al., 2001; Tavares et al., 2003). Even the new grain structures occurring under plastic working is resulted from a dynamic recrystallisation. During the explosive welding, ultra-fine grains occur as a result of a continuous increase in the misorientations between subgrains that developed with deformation (Kaibyshev, 2001).

During the SEM examination of the region of welding interface a local melting and band zone were observed in unheated specimen for the explosive loading rate of 1 (Figure 10). There was no evidence for intermetalic occurred at the interface. However, some diffusion or mixing at the interface during the explosive welding was seen with the evidence in the EDS analysis taken from the interface. It is seen from Table 1 that there are very little elements of $\mathrm{Si}, \mathrm{Cr}$ and $\mathrm{Ni}$ in low carbon alloy ( $\mathrm{E}$ 61820). However, after the completion of explosive welding, we can see large peaks of $\mathrm{Cr}, \mathrm{Ni}$ and $\mathrm{Si}$ (Figure 10). It means that a number of diffusion or mixing occurred during the explosive welding.

This can be attributed to the thermal conductivity of 304 austenitic stainless steel, $21.5 \mathrm{Wm}^{-1} \mathrm{~K}$ (Belyakow et al., 2003), which is lower than that of low carbon steel, (48 $\mathrm{Wm}^{-1} \mathrm{~K}$ ), at room temperature (Touloukian et al., 1977). During the solidification, this bond may be formed. According to Crossland (1976) during the welding, kinetic energy in the jet would be dissipated as heat causing melt at the interface.

EDS analysis indicated that the composition of local melding zone is different from that of low carbon steel. The presence of oxygen in this region can be attributed to the trapping of oxide from the surface during explosive welding.

Heat treatment consists of three stages including recovery, recrystallisation and grain growth. Completion 


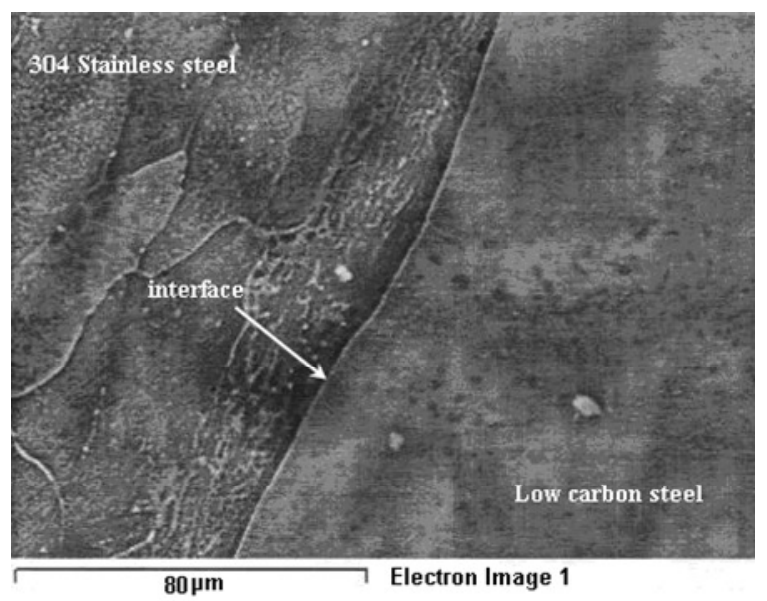

(a)

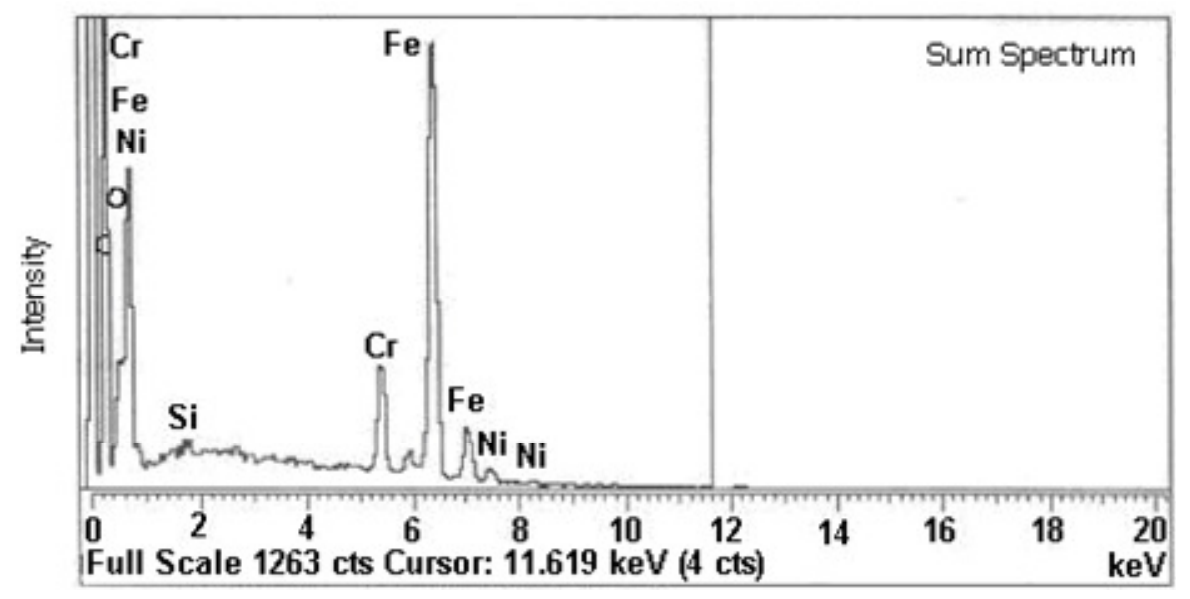

Figure 10. (a) SEM microgragh from interface of explosively cladded materials (no heat treatment, explosive loading rate of 1 ), b) EDS from the region of interface.

of these stages needs to time. During the recrystallisation, the density of dislocation also considerably decreases thus; the effect of strain hardening may be eliminated. Therefore, hardness values may be decreased and then grain size is progressively increased. The strain-hardened materials having higher energy are finalised lowering energy level and residual stress is also decreased with heat treatment. Heat treatment for longer durations, which resulted in increases in ductility while hardness and strength of the materials may be decreased (Abe, 1999). Longer heat treatment is caused lowering recrystallisation temperature of the material that have higher amount of strain-stress. Therefore, it is concluded that shorter time heat treatment $(1 \mathrm{~h}$ at $250 \mathrm{oC})$ is beneficial in spite of keeping the hardness level it decreases the residual stress. However, longer time heat treatment $(2-4 \mathrm{~h}$ at $250^{\circ} \mathrm{C}$ ) is not suitable due to bigger grain size (almost three times greater) and decreasing the hardness level. In this case, it might be advised that heat treatment can be beneficial only for medium and high carbon steel due to their higher hardness. Recent developments in explosive welding has been reported (Findik, 2011) showing comparable results of similar and dissimilar materials joined by explosive cladding.

Figure 11 shows the X-ray diffraction of the samples heat treated at $250^{\circ} \mathrm{C}$ for $4 \mathrm{~h}$. A few peaks observed in this diffraction the presence of the $\gamma, \alpha$ and $\varepsilon$ phases. The cladded plate is subjected to heat treatment as stressrelieving on heat treatment at $250^{\circ} \mathrm{C}$ for 1 to $4 \mathrm{~h}$ for all samples. As a result of this, microhardness values generally decrease. Lowering in hardness values may be attributed to changing of interface structure. As stated by Kaibyshev (2001), the annealing causes a reverse $\alpha \mathrm{l} \rightarrow \mathrm{Y}$ transformation and recrystallisation. It was determined that the grain size of newly formed austenite was limited. Due to the submicrocrystalline austenite structure a mean grain size of $30 \mu \mathrm{m}$ was formed in fine-grained samples. At the same time, the course grain size of austenite was uniform. Thus, microstructure formed during the dynamic 


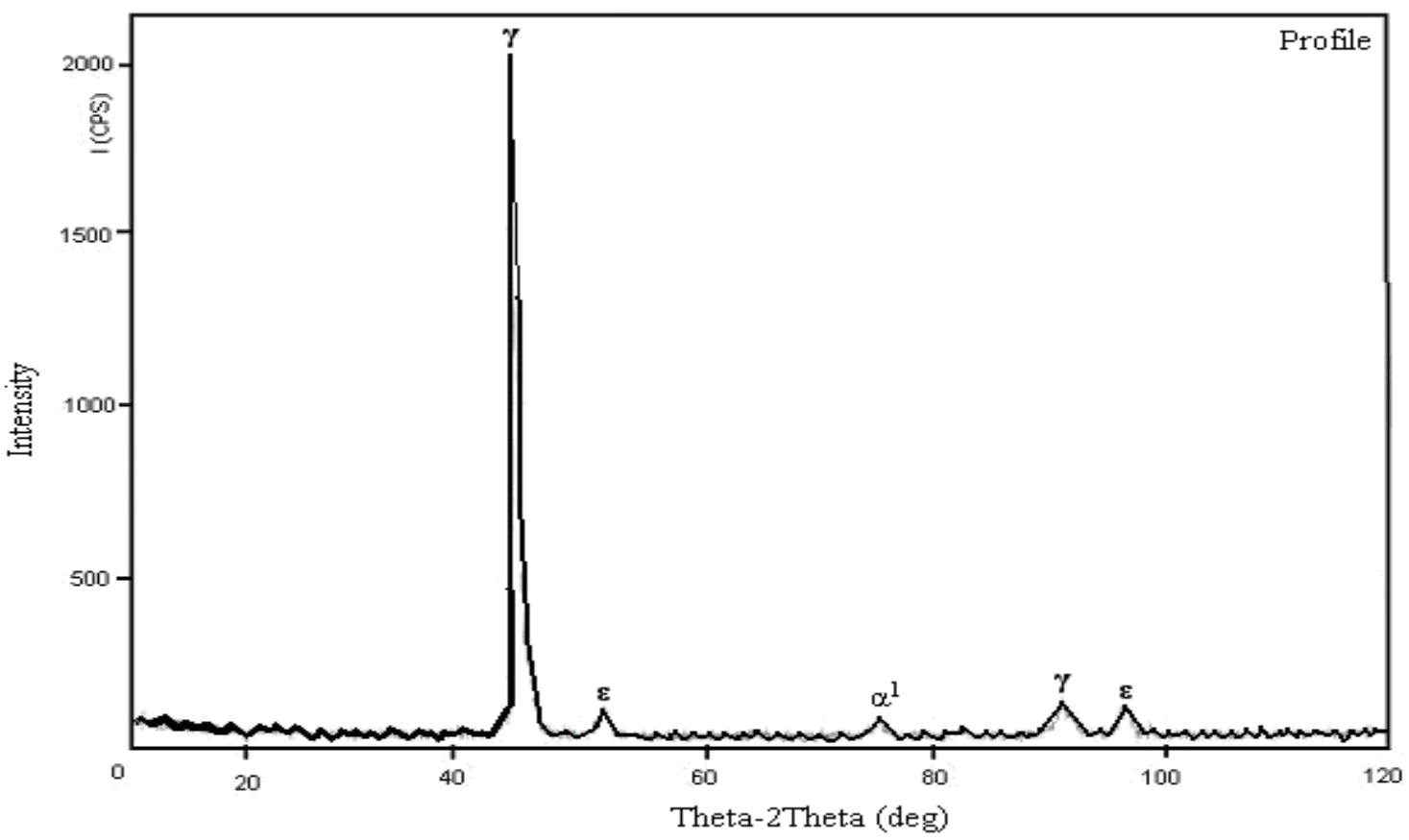

Figure 11. X-ray spectrum of as cladded materials by explosive welding.

deformation favourably influences the martensite transformation.

\section{Conclusions}

In this study, AISI 304 austenitic stainless steel cladded to low carbon steel by explosive welding method using various explosive loading. Subsequent heat treatment was applied on the weldment materials. Microstructural observations with hardness testing were carried out. The following conclusions can be drawn from the experimental results:

1. AISI 304 type of austenitic stainless steel and low carbon steel were successfully cladded by explosive joining technique.

2. The grains of the cladded materials at the interface were elongated in the explosion direction for both untreated and treated materials, which indicate that a high degree of plastic deformation occurred at the interface. However, the grains in the steel side become normal with the long heat treatment durations.

3. Higher microhardness values were observed at the interface due to the significant cold plastic deformation. However, those values decrease for locations away from the interface. The hardness values were affected by heat treatment especially for long heat treatment durations. This is attributed to changing of the microstructure at the interface.

4. The straight interface was usually obtained for the explosive loading of 1 . But, distinct wavy interface was observed in the loading rate of 2 .

5. Recrystallisation must have been occurred at the interface after the heat treatment resulting in a different size of grains.

6. Short time heat treatment is beneficial in spite of keeping the hardness level it decreases the residual stress. However, long time heat treatment is not proper due to bigger grain size and decreasing the hardness level.

\section{ACKNOWLEDGEMENTS}

The Authors would like to thank to MKE Barutsan Co., TR for provision of explosives and experimental facilities for explosion welding. Thanks also go to Dr. Ramazan Yilmaz and Dr. Mustafa Acarer due to valuable discussion during the course of this work.

\section{REFERENCES}

Abe A (1999). Numerical simulation of the plastic flow field near the bonding surface of explosive welding. J. Mater. Process Technol., 85(1-3): 162-165.

Acarer M, Demir B (2008). An investigation of mechanical and metallurgical properties of explosive welded aluminum-dual phase steel. Mater. Lett., 62(25): 4158-4160.

Acarer M, Gulenc B, Findik F (2003). Investigation of explosive welding parameters and their effects on microhardness and shear strength. Mater. Des., 24(8): 659-664.

Balasubrahmanian V, Rathinasabapathi M, Raghukandan K (1997). Modeling of process parameters in explosive cladding of mild steel and aluminum. J. Mater. Process Technol., 63(1-3): 83-88.

Belyakov A, Sakai T, Miura H (2001). Microstructure and deformation 
behavior of submicrocrystalline 304 stainless steel produced by severe plastic deformation. Mater. Sci. Eng. A, 319 (SI): 867-871.

Belyakov A, Tsuzaki K, Miura H, Sakai T (2003). Effect of initial microstructures on grain refinement in a stainless steel by large strain deformation. Acta Mater., 51(3): 847-861.

Brasher DG, Buther DJ (1995). Explosive welding: Principles and potentials. Adv. Mater. Process., 147(3): 37-38.

Crossland B (1971). The development of explosive welding and its application in engineering. Metals Mater. December, pp. 401-413.

Crossland B (1976). An experimental investigation of explosive welding parameters. Metals Technol., 3: 8-12.

Dieter GE (1988). Mechanical Metallurgy, McGraw-Hill, London.

Du XP, Liu HW, Guo C (2007). Interface fracture properties analysis of the stainless steel-aluminum bimetal. Rare Metal Mater. Eng., 36: 131-133.

Durgutlu A, Gulenc B, Findik F (2005). Examination of copper/stainless steel joints formed by explosive welding. Mater. Des., 26(6): 497-507.

Ege ES, Inal OT, Zimmerly CA (1998). Response surface study on production of explosively-welded aluminum-titanium laminates. J. Mater. Sci., 33: 5327-5338.

Fan Y, Tysoe B, Sim J, Mirkhani K, Sinclair AN (2003). Nondestructive evaluation of explosively welded clad rods by resonance acoustic spectroscopy. Ultrasonic, 41(5): 369-375.

Findik F (2011). Recent developments in explosive welding. Mater, Des., 32(3): 1081-1093.

Gerland M, Presles HN, Guin JP, Bertheau D (2000). Explosive cladding of a thin Ni-film to an aluminium alloy. Mater. Sci. Eng., A280(2): 311-319.

Ghaderi SH, Mori A, Hokamoto K (2008). Analysis of explosively welded aluminum-AZ31 magnesium alloy joints. Mater. Trans., 49(5): 11421147.

Ghanadzadeh A, Darviseh A (2003). Shock loading effect on the corrosion properties of low-carbon steel. Mater Chem. Phys., 82(1): 78-83.

Gulenc B (2008). Investigation of interface properties and weldability of aluminum and copper plates by explosive welding method. Mater. Des., 29(1): 275-278.

Han JH, Ahn JP, Shin MC (2003). Effect of interlayer thickness on shear deformation behavior of AA5083 aluminum alloy/SS41 steel plates manufactured by explosive welding. J Mater. Sci., 38(1): 13-18.

Inal TO, Zimmerly CA (1997). Processing of Materials with Explosives, 9th International Metallurgy and Materials Congress, (Ed.: Kayir, Y.Z., Editorial Office, Istanbul), Istanbul, Turkey, p. 751.

Kaçar R, Acarer M (2003). Microstructure-property relationship in explosively welded duplex stainless steel-steel. Mater. Sci. Eng., A363(1-2): 290-296.

Kahraman N, Gulenc B (2005). Microstructural and mechanical properties of $\mathrm{Cu}$-Ti plates bonded through explosive welding process. J. Mater. Process Technol., 169(1): 67-71.

Kahraman N, Gulenc B, Findik F (2005). Joining of titanium/stainless steel by explosive welding and effect on interface. J. Mater. Process Technol., 169(2): 127-133.

Kahraman N, Gulenc B, Findik F (2007). Corrosion and mechanicalmicro structural aspects of dissimilar joints of Ti-6Al-4V and Al plates. Int. J. Impact Eng., 34(8): 1423-1432.

Kaibyshev OA (2001). Grain refinement in commercial alloys due to high plastic deformations and phase transformations. J. Mater. Process Technol., 117(3): 300-306.

Linse VD, Lalwaney NS (1984). Explosive welding. J. Metals, 36(5): 6265.

Livne Z, Munitz A (1987). Characterization of explosively bonded iron and copper plates. J. Mater. Sci., 22(4): 1495-1500.

Metal Handbook (1983). Arc Welding of Stainless Steel, 8th Edition, Welding and Brazing, Am. Soc. Metal, 6: 245
Mousavi SAAA, Sartangi PF (2008). Effect of post-weld heat treatment on the interface microstructure of explosively welded titaniumstainless steel composite. Mater. Sci. Eng. A-Struct. Mater. Properties Microstruct. Process., 494(1-2): 329-336.

Mousavi SAAA, Sartangi PF (2009). Experimental investigation of explosive welding of $\mathrm{cp}$-titanium/AISI 304 stainless steel. Mater. Des., 30(3): 459-468.

Mudali UK, Rao BMA, Shanmugam K (2003). Corrosion and microstructural aspects of dissimilar joints of titanium and type $304 \mathrm{~L}$ stainless steel. J. Nuclear Mater., 321(1): 40-48.

O'sullivan D, Cottrell M, Meszaros I (2003). The Characterization of Work-hardened Austenitic Stainless Steel by NDT Micro-Magnetic Techniques, NDT\&E Int.

Smith WF (2000). Stainless Steel: Structure and Properties of Engineering Materials, Chapter 5. Trans: Erdogan, M., Ankara, 1: 169.

Takahashi S, Echigoya J, Ueda T (2001). Martensitic transformation due to plastic deformation and magnetic properties in SUS 304 stainless steel. J. Mater. Process Technol., 108(2): 213-216.

Tavares SSM, Gunderov D, Stolyarov V, Neto JM (2003). Phase transformation induced by severe plastic deformation in the AISI 304L stainless steel. Mater. Sci. Eng. A, 358(1-2): 32-36.

Touloukian YS, Kirby RE, Lee TYR (1977). Thermal Physical Properties of Materials. IFI/Plenum Press, New York, B: 1138.

Watanabe M, Kumai S (2009). Interfacial Morphology of Magnetic Pulse Welded Aluminum/Aluminum and Copper/Copper Lap Joints. Mater. Trans., 50(2): 286-292. 